\title{
Increasing Energy Efficiency in the Food and Beverage Industry: A Human-Centered Design Approach
}

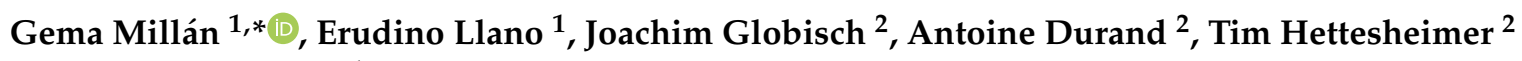 \\ and Eduardo Alcalde ${ }^{1}$ \\ 1 Fundacion CIRCE, 50018 Zaragoza, Spain; ellano@fcirce.es (E.L.); ealcalde@fcirce.es (E.A.) \\ 2 Fraunhofer ISI, 76139 Karlsruhe, Germany; Joachim.Globisch@isi.fraunhofer.de (J.G.); \\ Antoine.Durand@isi.fraunhofer.de (A.D.); Tim.Hettesheimer@isi.fraunhofer.de (T.H.) \\ * Correspondence: gmillan@fcirce.es
}

Received: 4 August 2020; Accepted: 25 August 2020; Published: 28 August 2020

check for updates

\begin{abstract}
Energy efficiency in companies is addressed by established tools or procedures, such as energy audits or the implementation of an energy management system in accordance with the Energy Efficiency Directive. Both options indistinctly provide sufficient information for companies to identify opportunities for improvement and savings in their energy costs. However, the influence of cultural and behavioral aspects on employees and the organizational and structural configuration of companies impacts the effectiveness of these tools. In this regard, within the framework of the INDUCE "Towards a sustainable agro-food Industry: Capacity building programmes in Energy Efficiency" project, which is an $\mathrm{H} 2020$ research project focused on the food and beverage industry, an innovative methodology based on the human-centered design approach has been designed to motivate and empower the key actors of companies by creating an energy culture that increases energy efficiency. This methodology, which internalizes the procedures and philosophy of continuous improvement of an energy management system, allows companies to adopt different models adapted to each situation in order to acquire an energy-efficiency culture that enables actions to be carried out in companies more effectively and with long-term impact. This paper describes the methodology and its implementation and validation within 11 pilot companies in France, Germany, Spain, and The Netherlands, providing some representative results.
\end{abstract}

Keywords: energy efficiency; energy-management systems; energy audits; food and beverage industrial industry; human-centered design; ISO 50001; lesson-study approach

\section{Introduction}

The INDUCE "Towards a sustainable agro-food Industry: Capacity building programmes in Energy Efficiency" is an H2020 research project within the topic EE-15-2017-increasing capacities for actual implementation of energy-efficiency measures in industry and services, in the funding scheme of coordination and support action (CSA). The main objective of the INDUCE project is to design a capacity-building program together with an innovative methodology that will be made available to those companies aiming to increase their energy efficiency. The INDUCE project is framed in the different directives and regulations to which the project has tried to contribute. The most important one is the European Energy Efficiency Directive (EED) 2012/27/EU, which requires Member States to use energy more efficiently at all stages of the energy chain and, in particular, at the industrial and services level $[1,2]$. In this sense, the INDUCE project has actively worked with enterprises in the food and beverage industry, within the agro-industrial sector, to promote better energy use. This sector is characterized by its diversity of company typologies between large enterprises and small and medium enterprises (SMEs) and its types of processes and associated activities, as well as by 
the importance of the sector at the European level. The food and beverage industry has the highest expected reduction in energy intensity toward 2050 [3]; it is the biggest consumer of energy and causes $67 \%$ of the greenhouse gas (GHG) emissions from the agri-food sector. Companies from Germany, France, Spain, and The Netherlands have contributed to the project; together, these Member States represent $46 \%$ of the food and beverage industry in Europe [4].

With the aim of promoting better use of energy in Europe, the EED establishes different goals and tools to achieve them. As laid down in Article 8 \$2 of the EED, "Member States shall develop programmes that encourage small and medium enterprises (SMEs) to undergo energy audits and the subsequent implementation of the recommendations from these audits" [1]. In the same direction, according to EED Article 8 paragraph 4, energy audits have to be carried out every four years in non-SMEs. The EED lists possible relevant European and international standards, such as EN 16247-1 (energy audits) and EN ISO 50,001 (energy management systems), or even EN ISO 14,001 (environmental management systems) [1,2,5], for these purposes. Furthermore, the Member States shall put in place so-called energy efficiency obligation schemes (EEOSs) $[1,6]$ to facilitate or ensure that the objectives set out in the regulations are achieved. The elaboration of energy audits, as well as the implementation of management systems, allows companies to identify opportunities to improve their energy efficiency. One of the lessons learnt about the energy efficiency of industries (European Commission, Good practice in energy efficiency, p. 25) was that despite the relatively low energy savings per company that SMEs have, these companies could offer considerable cost-effective savings potential [6]. However, in this respect, since these companies have no requirement or obligation to carry out any of the actions mentioned above, unless promoted at the national level, the expected results have not been so favorable, considering that more than $98 \%$ of European enterprises are of this type [7].

The INDUCE project has addressed how to enhance energy efficiency actions in companies within the food and beverage industry. Based on other initiatives and experiences where a large number of energy audits were conducted in Europe, such as the TESLA "Transferring Energy Save Laid on Agroindustry" project (688520) [6] or the SCoOPE "Saving Cooperative Energy" project (695985) in the agro-food sector, it is deduced that SMEs do not have a need supported by European regulations, but neither do they have enough information about them to know what options they have in case they are required to improve their energy performance. There is still no sense of urgency to pay attention to energy efficiency as a means of cost reduction. Thus, energy efficiency is often not on the agenda in everyday routines when making investments or in conversations within companies or between companies, suppliers, and even energy advisors. On the other hand, recommendations made through an energy audit are not guaranteed to be properly implemented, since the implementation depends on people's behavior and enterprises' energy culture and supply chains $[6,8]$. The effectiveness of these actions relies on board and employee behavior, which is shaped by organizational, structural, and cultural aspects. Since these aspects are not fully considered in current training and management systems, there is a need to ensure that their recommendations lead to the actual implementation of energy-efficiency measures [9].

Thus, within the INDUCE project, an innovative methodology, from now on, the INDUCE methodology has been developed based on certain barriers, enhancing possible drivers to help improve energy efficiency actions in companies. This methodology is defined as following a human-centered design (HCD) approach in which all actions are conducted in close cooperation with companies. Moreover, Wohlfarth et al. [6] identified several barriers for energy efficiency in companies: the lack of information is one of the most important aspects detected [10], mainly focused on energy audits, costs and benefits, technology providers, difficulties in assessing the risks associated with new technology, and lack of trust in new solutions and information sources. In this sense, the INDUCE methodology links knowledge transfer on energy efficiency with behavioral and organizational change models. In light of this, specific and personalized training for each situation and regarding organizational, 
structural, and cultural aspects of a company is provided. It is important to highlight that approximately $50 \%$ of the untapped energy efficiency potential is related to structural and behavioral change [11-13].

The INDUCE methodology was defined, tested, and validated with the support of several pilot companies distributed among the four Member States mentioned above. Initially, 15 pilot companies were involved, although, eventually, only 13 of them actively participated in the whole process.

The main objective is to generate a structure for capacity-building programs tailormade to a company's needs, requirements, and interests. Using these approaches, the INDUCE methodology was designed with the goal to break down some of the barriers detected, thanks to the effective delivery of training and information, adapted to the specific situation of each company. In this regard, in the INDUCE methodology, activities and strategies are expected to overcome some of these obstacles and to achieve improvements in the company.

As detailed in this paper, the INDUCE methodology provides different sequential phases that link capacity-building programs on energy efficiency with behavioral and organizational models to address the demand for behavioral and cultural interventions and to support energy-efficiency measures and tools, whether an energy audit or an energy management system [1].

This paper presents all of the phases and actions that make up the INDUCE methodology, as well as the most representative results achieved during the project, after completion of the actions with the pilot companies. In this sense, the INDUCE project tries to explore further and to provide comprehensive information on the situation of the whole food and beverage industry in Europe.

\section{Materials and Methods}

\subsection{INDUCE Methodology Overview}

At the beginning of the INDUCE project, before defining the methodology, an in-depth study of the situation of the food and beverage industry at the energy level was carried out, not only in the countries involved, but also throughout Europe [14]. At the same time, other similar initiatives were analyzed, both past and present, which addressed the same problem and attempted to promote energy efficiency, as well as efficiency measures with the greatest impact and potential that could be applied [15]. Therefore, the initial work carried out within the INDUCE project determined the starting point for defining the actions and objectives that would eventually define the INDUCE methodology.

Then, different theories and studies that had consulted on energy, behavioral, and organizational change thus far were put into practice in the pilot companies by performing several actions to facilitate the first steps of the definition of the INDUCE methodology.

The INDUCE methodology, as is detailed in this section, is composed of four phases: (1) Inspiration, (2) Ideation, (3) Implementation, and (4) Monitoring. The first phase, "Inspiration," is the most innovative, important, and complex, as well as the most time consuming. Different assessments and analyses were carried out, where both energy and cultural, behavioral, and organizational approaches were combined. Once all of the actions in the Inspiration phase had been carried out, the next phase, "Ideation," developed the design of the training programs, both general (template) and adapted to each of the cases in each pilot company. The general template of the training program of the INDUCE project was based on a previous prospective study also developed at the beginning of the project [16]. Each of the training programs was implemented in each of the pilot companies. Once implemented, each case was analyzed to test both the methodology itself, in order to validate and adjust it, and to review the impact it would have generated in the energy and behavioral aspects of each company.

Therefore, this paper presents the methodology and details of each of the phases, such as its meaning, objectives, and results can be used in later phases. In this sense, some of the actions, mainly in the Ideation phase, are listed, but neither their origin nor how they have been defined are addressed. 


\subsection{INDUCE Methodology}

The INDUCE methodology looks for the implementation of capacity-building programs in energy efficiency based on an HCD approach, leading to the ad-hoc design of training courses and interventions that align the motivation of involved key actors with an energy efficiency culture. This methodology constitutes an original way of designing and generating adapted capacity-building programs, being a tool that allows training providers, advisors, and trainers to generate training solutions regarding energy efficiency and energy management for companies. Although this methodology has been designed, tested, and validated in the food and beverage industry, the procedure has been defined in such a way that is replicable in any company in any sector, whether industrial or services.

The HCD approach is a problem-solving approach with a great potential to provide and generate innovations. This paradigm is based on the concept that whatever innovation/product/service that a company wants to produce, it is necessary to consider three main dimensions, namely desirability, viability, and feasibility, being the desire of the future users/consumers the first point to address [17] (p. 14). The main concept in this approach is that those people who try to generate an innovative product, a training program, a service, or another social, economic, or environmental solution must have knowledge of the desires, fears, hopes, and expectations of the future people who will use the solution. In line with this, a significant amount of time during the solution's generation process has to be linked to the research activities of users, trying to empathize with them, as well as to find a real understanding of their points of view, opinions, and worldviews [17]. This effort is the key point to produce real and useful solutions based on the needs of the people. Indeed, this approach considers that "the people who face those problems every day are the ones who hold the key to their answer" [17] (p. 9). The HCD approach is applied through three main phases, namely, Inspiration, Ideation, and Implementation, with the following characteristics [17]:

1. Inspiration: In this phase, the key actors are observed to identify their ideas, opinions, desires, expectations, etc., regarding the challenge needing to be solved.

2. Ideation: Here, the opportunities are identified, the ideas are generated, and prototypes of the hypothetical solution are made. The prototypes are tested, receiving feedback, and being adjusted to generate more sophisticated prototypes until the final version of the solution is achieved.

3. Implementation: In this phase, the solution is implemented in the market in real life.

In addition, and in the specific case of the INDUCE project, the methodology includes a fourth phase dedicated to "Monitoring" in order to evaluate the outcomes and to agree on follow-up activities with the company to determine the impact that all of these actions have (Figure 1).

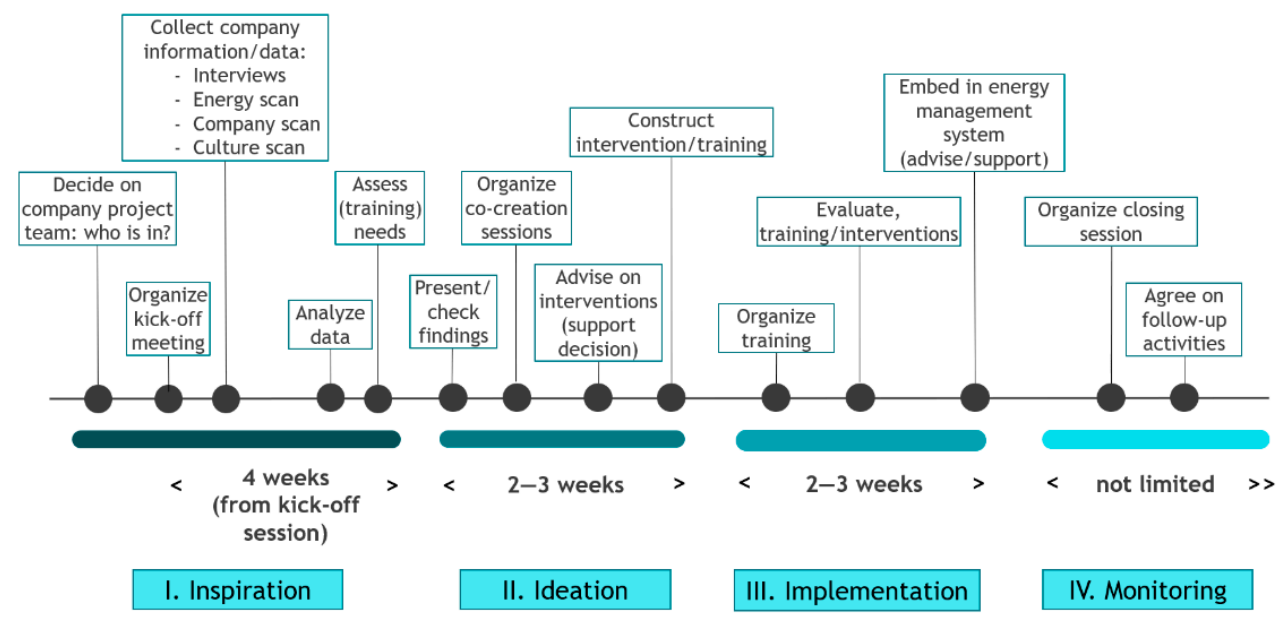

INDUCE HUMAN-CENTERED DESIGN APPROACH

Figure 1. The four phases of the INDUCE methodology (source: INDUCE project). 
Phase I of the INDUCE methodology, Inspiration, is where the data collection is performed by means of interviews, surveys, observations of people's behavior, etc. The three main aspects that are considered in the INDUCE methodology (Figure 2) during this phase of Inspiration are:

(1) At the company level, the barriers and opportunities of the entity are identified, as well as the characteristics of the organization, its structure, the roles of the different actors, etc. All of these aspects are key points in this methodology, which considers that technical and non-technical aspects have the same importance. The key point here is to receive all of the necessary insights for obtaining a realistic picture of the situation of the company, being fully aware of the technical points but also of those phenomena caused by organizational culture, as well as the relationship among the workers. These inputs are mainly obtained thanks to different actions, listed chronologically as: first contact, discuss benefits, agreement, energy scan, interviews, and culture scan (Figure 1). The project also performs - and encourages future replicators to perform-meetings with key people and managers, as well as to observe carefully the reality of the organization, trying to comprehend the real hopes, expectations, needs, and interest of the members of the company. In this first part, it is also crucial to determine who the managers and the members of the direction department are, as well as to identify who should be involved in the project-who will support the INDUCE experts in their labors and who will be the future trainees?

(2) Technically speaking, the INDUCE methodology considers the energy performance of a company in depth. Because this methodology did not foresee direct energy assessments, the insights in this respect are obtained by taking into account energy audits and energy assessments performed in the past, energy-efficiency measures already developed or planned, data obtained from internal diagnosis, or daily maintenance tasks, etc.

(3) As a unique feature, the INDUCE methodology includes cultural analysis of the entities: their habits, daily routines, informal roles, the nature of their relationships and, ultimately, all those non-technical aspects that explain the reason why a company is the way it is. Here, the key point in the work of the INDUCE experts or those replicators of the INDUCE methodology is to develop an empathic and open-minded approach. Based on the study developed within the INDUCE project, it was determined that these experts must understand the opinions, wishes, hopes, expectations, etc., of future trainees, as well as to comprehend a company's social structure, the relationship between the departments, and the general organization culture.

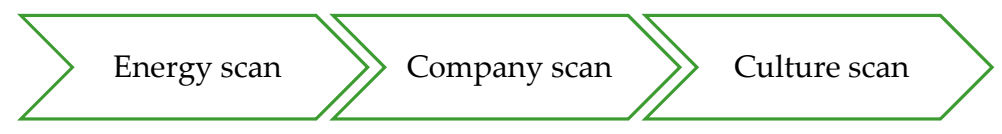

Figure 2. Key actions in Phase I: Inspiration (source: INDUCE project).

The Phase II is the Ideation part of the HCD approach. As previously mentioned, this is the phase where training experts generate prototypical solutions that, in the case of the INDUCE project, are prototypes of capacity-building programs adapted to the needs of each company. This adaptation and the building of the main scheme of the training prototype can be performed thanks to the inputs collected during the Inspiration phase. To do that, the INDUCE project developed several tools and materials ordered and organized according to Figure 3, which allow trainers to build this first version of the training program, namely, training formats templates, training materials, dynamics schemes, etc.

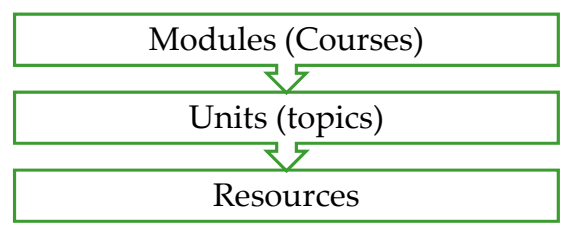

Figure 3. Capacity-building program structure (source: INDUCE project). 
Then, when this first version of the training is ready, the methodology expects the realization of the "co-creation session" (Figure 1) to check if the prototype meets all of the necessary requirements. Co-creation sessions consist of a meeting with the higher management departments of an organization or with the energy/maintenance manager. In this meeting, the experts who performed the training are able to check that the scan of the Inspiration phase has obtained a correct view of the company. Furthermore, they take advantage of this meeting for presenting the main characteristics of the prototype to the higher departments of the company with the purpose of receiving their feedback so as to be able to prepare the final training version. Thanks to this co-creation session, several adjustments are likely to be implemented after considering the feedback. For instance, changes in the duration, the complexity of the contents, or the approach used for the training.

Once this co-creation session has finished, the capacity-building program prototype can be considered as a consolidated version, being "to test it" at the necessary next step. In this respect, the procedure of testing in the INDUCE methodology was inspired by the lesson-study approach, which can be considered as one of the most empirical pedagogical approaches where observation and continual improvement are key. "Lesson study is a Japanese practice where teachers conduct a systematic inquiry into their pedagogical practice by closely examining a lesson and its delivery" $[18,19]$. This approach is divided into four steps (Figure 4) [20], similar to and with the same philosophy as the Deming Cycle [21], where the execution of the training plan is an opportunity to extract weaknesses and to design improvements.

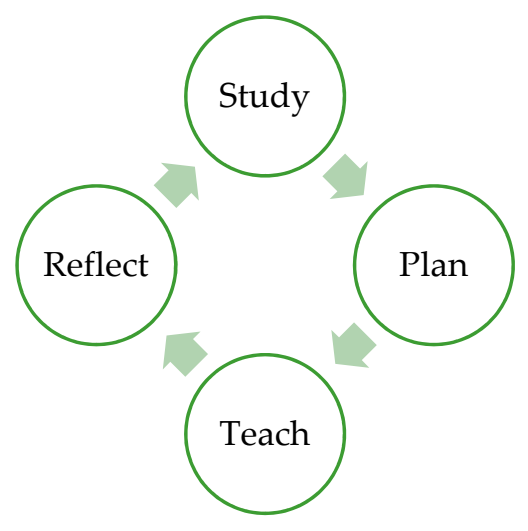

Figure 4. Lesson-study approach [20].

In the INDUCE methodology, which is based on the HCD approach and inspired by the lesson-study approach, the testing part is the key moment in which trainers can determine if the learning approach, the content of the training, and format of the actions are appropriate for the target group, i.e., the company's workers (Figure 5).

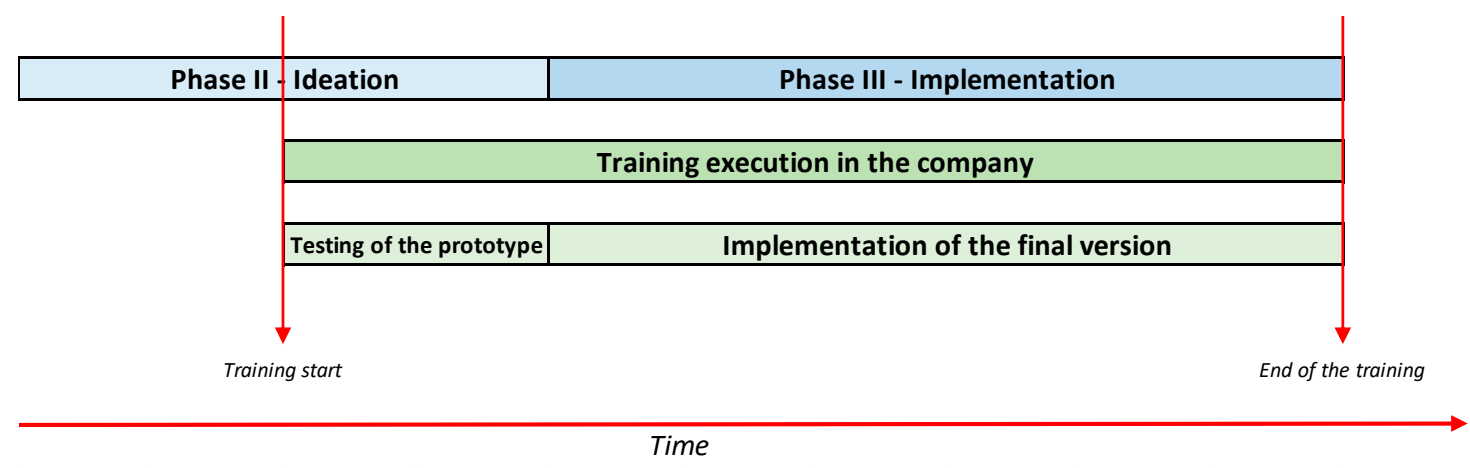

Figure 5. Testing location inside of the training execution and INDUCE methodology (source: INDUCE project). 
The methodology takes advantage of the beginning of the training to perform this test of the training prototype. At this moment, the trainer can check if the trainees are satisfied with the approach used. This is a real-time adaptation opportunity that must consider all questions and comments expressed in class.

Having completed the adaptation through the integration of finishing touches, the final version of the training program is obtained, and the training activities can continue being implemented during execution of the rest of the training program, which constitutes Phase III-Implementation of the HCD approach.

Finally, as the last step of the INDUCE methodology, once the training has been implemented, the methodology highlights the importance of checking the performance of the training through evaluation exercises, surveys, and discussions in order to validate the training program and to perform improvements for future training actions. This final step constitutes Phase IV—Monitoring and evaluation.

Two main reasons justify this last step of validation: (1) On the one hand, the assessment allows us to validate the capacity-building program, as well as to identify the impact of the implementation of the methodology in the company and (2) on the other hand, this part generates inputs that are necessary to take into account in case an interested new company decides to implement this methodology.

Regarding the first reason, within the project, some of the actions conducted during Phase II (Ideation) were performed again in order to evaluate the impact of the training in the pilot companies. Thus, after updating the information six months after the training, it was possible to extract information on the potential impact, thanks to surveys that evaluated the training and the achievement of the initially established objectives. Furthermore, a new and updated energy scan allowed us to see the potential for energy savings, the number of energy measures that could be implemented, and the investment capacity that the company considered to carry out actions in order to improve its energy performance. Seeing the pre- and post-training implementation differences, it was possible to evaluate the impact that all of the phases of the INDUCE methodology combined had had on the pilot companies and to extrapolate the conclusions to the whole food and beverage industry in Europe.

The Monitoring phase of the methodology is likely to be ignored or underestimated once the training program has been carried out, but it is of great importance in the process, not only because it provides closure, but also because it provides very useful information for both the company and the trainer. If the company wants to implement certain measures, among which is the training and awareness of its employees to achieve greater effectiveness and to improve their energy performance, it needs to know if the actions they have carried out have been useful and how to improve them. Furthermore, under the philosophy of the continuous improvement process (Plan-Do-Check-Act or Adjust), applied, for example, in energy management (ISO 50001:2018) [21,22], the INDUCE methodology can be carried out once, but periodically addressed again, only in those aspects that are more relevant to the company's needs or that need to be improved.

As mentioned above, the implementation of the methodology was carried out in 13 pilot enterprises in the four countries involved. After the Monitoring phase within the methodology, it could be seen that two of them, due to their large size, provided data and results that distorted the sample of the INDUCE project. Therefore, in order to show results of the project and to provide information that may be useful, only 11 companies were considered for the impact assessment.

\section{Results}

As previously introduced, the food and beverage industry is one of the most energy-intensive of the industrial sectors in the European Union (EU), being a major consumer of energy; the amount of energy necessary to process, pack, and bring food to European citizens in 2013 represented approximately $26 \%$ of the final energy consumption in the EU [4]. Due to the intensity of energy consumption and the reduced development of improvements within this sector in the EU, it has great potential for improvement and for the highest expected reduction in energy intensity ratio, defined by the European 
Environmental Agency (EEA) calculated between gross inland energy consumption measured in kilotons of oil equivalent (ktoe) and gross domestic product in million euros (MioEUR) for 2010 market prices, toward 2050 in the EU. The EU energy-intensive ratio in the most representative sectors and their variations are shown in Table 1 [3].

Table 1. EU energy-intensive industrial sectors and their reductions in energy intensity (source: [9]).

\begin{tabular}{cccc}
\hline Sector & Energy Intensity (2015) & Energy Intensity (2050) & $\begin{array}{c}\text { Energy Intensity Ratio } \\
\text { Variation 2015-2050 }\end{array}$ \\
\hline Food and beverage & 0.023 ktoe/MioEUR & 0.007 ktoe/MioEUR & $-70.6 \%$ \\
Machinery & $0.012 \mathrm{ktoe} / \mathrm{MioEUR}$ & $0.006 \mathrm{ktoe} / \mathrm{MioEUR}$ & $-51.6 \%$ \\
Pulp, paper, & 0.389 toe/ton & 0.292 toe/ton & $-24.9 \%$ \\
and paperboard & $0.078 \mathrm{ktoe} / \mathrm{MioEUR}$ & $0.065 \mathrm{ktoe} / \mathrm{MioEUR}$ & $-17.1 \%$ \\
Non-ferrous metals & 0.341 toe/ton & 0.299 toe/ton & $-12.3 \%$ \\
Iron and steel & 0.08 ktoe/MioEUR & $0.076 \mathrm{ktoe} / \mathrm{MioEUR}$ & $-5 \%$ \\
Chemical and & 0.118 toe/ton & 0.115 toe/ton & $-2.5 \%$ \\
pharmaceutical & 0.066 toe/ton & 0.068 toe/ton & $3 \%$ \\
Non-metallic minerals & Coke and refined & & \\
petroleum & & &
\end{tabular}

This paper includes some of the results achieved in the INDUCE project regarding economic and energy indicators.

As mentioned before, at the beginning of the project, an in-depth study of the food and beverage industry in Europe was carried out to establish a starting point [14]. From this study, it was extracted that there is great heterogeneity, mainly due to the number of types of processes and the variability of companies. For instance, the annual energy consumption ranged from less than $1 \mathrm{GWh}$ to more than $175 \mathrm{GWh}$ (as a clear exception). In addition, the estimated energy savings ranged from less than $1 \%$ to more than $16 \%$ for a rather ambitious company. The main objective of this previous study was to determine a benchmarking baseline that would help calculate the impact on the sector from the measures and actions carried out, both in the project with the pilot companies and afterward with the new companies, promoted by the implementation of the INDUCE methodology. However, due to the great variations detected between countries, it was not possible to precisely define a benchmarking baseline.

This study tried to draw on the companies that participated in the project. In this sense, in addition to the pilot companies, the INDUCE project established a replication phase, during the last period of the project in which it was hoped to involve 300 companies from the food and beverage industry in Europe. This replication phase was expected to begin in March 2020. For this purpose, a community of more than 60 trainers was trained on the INDUCE methodology in the four countries, but the COVID-19 crisis did not allow or made it difficult to carry out promotion and actions in order to get new companies to adopt this methodology and to contribute with their results to evaluate the total impact of the project.

Thus, finally, the impact of the INDUCE project was evaluated considering the sample of 11 companies. From this sample, the average values were determined, as shown in Table 2. In order to provide the average values, the energy scan carried out during Phase I (Figure 1) was repeated, so as to be able to compare and know the impact that Phase III (Figure 1) could have on the different companies. According to the results, only 11 companies provided valid data to be presented, mainly because of the difficulty of the sector, due to the heterogeneity and versatility in activity and size, in this case, of the companies involved in the INDUCE project. 
Table 2. Average values of the INDUCE project (source: INDUCE project).

\begin{tabular}{ccc}
\hline \multicolumn{2}{c}{ Energy, Economic, and Environmental Impact of the INDUCE Project } \\
\hline Impact & Value/Enterprise & Unit \\
\hline Investment & 68,824 & EUR/year/enterprise \\
Energy savings (final energy) & $1,296,882$ & $\mathrm{kWh} /$ year/enterprise \\
Electricity & 254,478 & $\mathrm{kWh} /$ year/enterprise \\
Natural gas & $1,042,405$ & $\mathrm{kWh} /$ year/enterprise \\
Energy savings (primary energy) & $1,800,000$ & $\mathrm{kWh} /$ year/enterprise \\
Energy costs avoided & 63,501 & EUR/year/enterprise \\
Electricity costs avoided & 34,746 & EUR/year/enterprise \\
Natural gas costs avoided & 28,755 & EUR/year/enterprise \\
Greenhouse gas (GHG) avoided (EU electricity mix) & 329,672 & $\mathrm{kgCO} /$ /year/enterprise \\
GHG avoided due to electricity & 75,325 & $\mathrm{kgCO} /$ /year/enterprise \\
GHG avoided due to natural gas & 254,347 & $\mathrm{kgCO} /$ year/enterprise \\
\hline
\end{tabular}

Once the results were determined, and seeing how unrepresentative the sample was, the analysis was completed by updating the data included in the first analysis of the sector at the energy and economic level. Based on the data provided by the EUROSTAT Database, available until 2017 or even 2018, although they are not complete due to changes (i.e., Brexit), it is possible to show again the situation of the food and beverage sector in Europe (Table 3), with regard to its energy consumption compared to other sectors in Europe (Figure 6). Similarly, since the information obtained from the INDUCE project is not very representative, in addition to the information provided by EUROSTAT, additional data are taken from other sources, such as those collected in the databases developed by the Odyssee-Mure "a decision support tool for energy efficiency policy evaluation" project (696077).

Finally, as detailed from the beginning, the INDUCE project addresses not only energy but also cultural, behavioral, and organizational aspects. Just as an average value has been obtained from the data collected in the 11 pilot companies at the energy and economic level, in the case of cultural and behavioral analysis, the responses are very specific to each company, and these data have been collected within confidential documents, so it is not possible to show quantifiable results that evaluate the level of satisfaction or the degree of penetration that the INDUCE methodology has had in the companies. However, in order to be able to provide information in this sense, various interviews were requested, collecting some testimonies in the final stage of the project (at least one per country), which were included as promotional material. From these testimonies, the initial impact generated by the initial phase, i.e., Phase I (Inspiration), on the key actors is highlighted, as it is certainly unusual, but once the methodology was implemented, they recognized the great usefulness of the actions and thanked them. They felt that the training they received was effective and, furthermore, provided thanks for the tools they were provided with; in several cases, they even developed an action plan to ensure continuity of the methodology.

Table 3. Relevance of manufacturing food products and beverages by employees and enterprises, as well as the value added and turnover in 2017-2018 for the European Union (source: EUROSTAT data table SBS_na_ind_r2).

\begin{tabular}{cccccc}
\hline $\begin{array}{c}\text { (Nomenclature of Economic } \\
\text { Activities) NACE }\end{array}$ & $\begin{array}{c}\text { Employees } \\
\text { (Number) }\end{array}$ & $\begin{array}{c}\text { Enterprises } \\
\text { (Number) }\end{array}$ & $\begin{array}{c}\text { Value Added } \\
\text { (MioEUR) }\end{array}$ & $\begin{array}{c}\text { Production Value } \\
\text { (MioEUR) }\end{array}$ & $\begin{array}{c}\text { Turnover } \\
\text { (MioEUR) }\end{array}$ \\
\hline $\begin{array}{c}\text { C10-Manufacture of } \\
\text { food products }\end{array}$ & $4,120,893$ & 265,094 & 199,000 & 931,000 & $1,026,033$ \\
$\begin{array}{c}\text { C11-Manufacture } \\
\text { of beverages } \\
\text { TOTAL }\end{array}$ & 448,146 & 31,000 & 47,210 & 168,000 & 174,963 \\
& $4,569,039$ & 296,094 & 246,210 & $1,099,000$ & $1,200,997$ \\
\hline
\end{tabular}




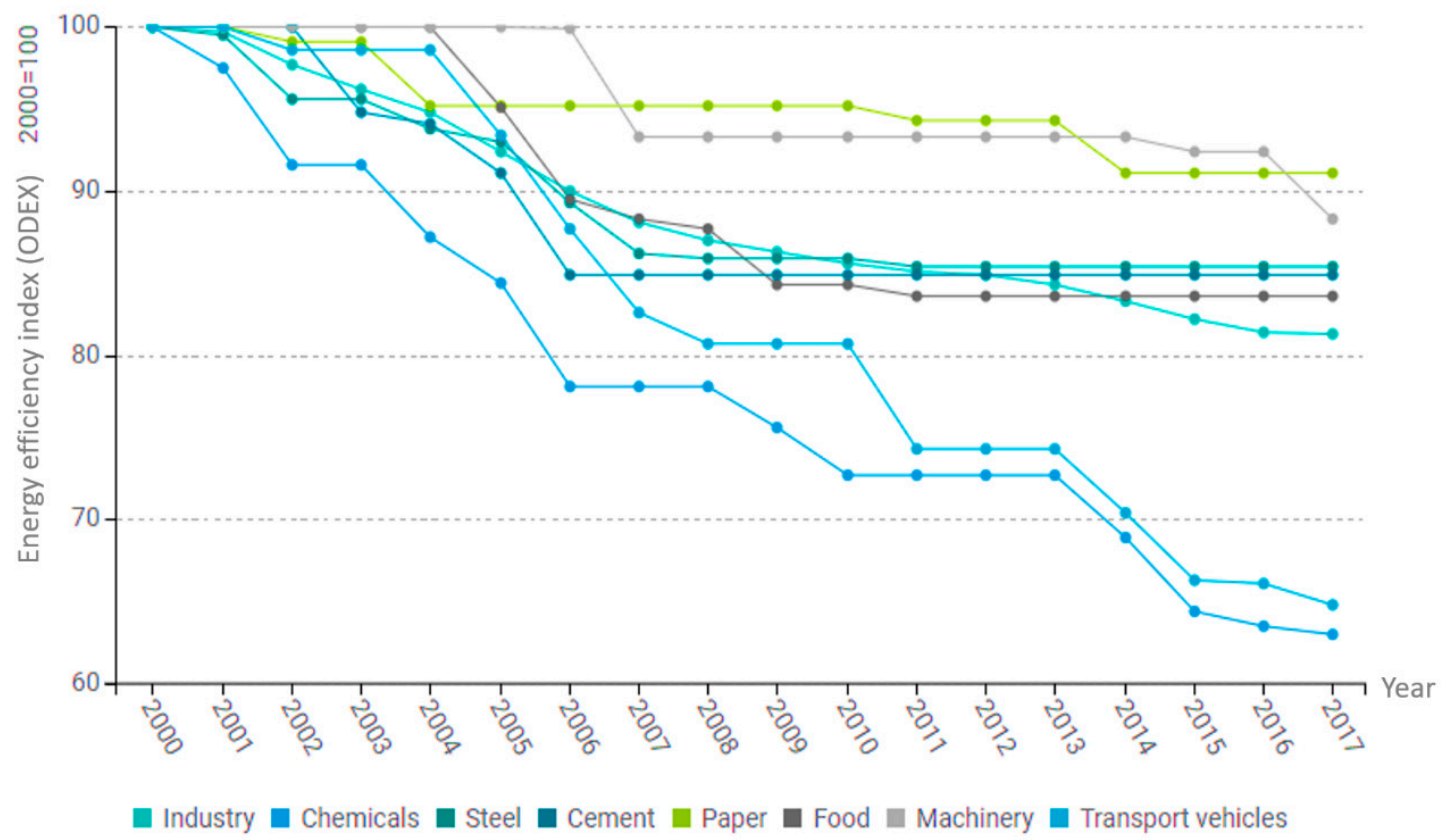

Figure 6. Evolution of the energy efficiency index by type of industry in the EU-28 (source: Odyssee-Mure).

\section{Discussion}

With reference to the results and experiences shown in this paper, the food and beverage sector is too large and heterogeneous to be addressed as a whole. It is made up of such disparate subsectors in terms of process typologies, but at the same time with great heterogeneity in terms of company typologies, that the sample with which the INDUCE project finally worked is small and is not representative for obtaining conclusions or defining a series of indicators that can be used for the whole sector. In this sense, even doing a prospective study of the whole sector at the European level is very complicated [14], since in each country, due to the typology of farming or the cattle industry, there is a very different distribution of subsectors. In the previous studies already commented on in this article, such as the TESLA and SCoOPE projects, where more than 100 companies were involved, the agro-industrial sector was addressed, but companies in the same subsectors were evaluated and compared, and indicators were obtained by the type of activity, such as oil, wine, or dairy, thus resulting in better conclusions. From the experience acquired in the INDUCE project, a need for a greater number of companies participating and implementing the defined methodology has arisen, and even to be able to group and classify these companies according to activity, size, turnover, volume of production, or value added in accordance with the factors that were determined in the evaluation carried out in the project (Table 3).

\section{Conclusions}

Based on the developments since the publication of the EED in 2012, as well as the studies and analyses carried out in the industrial sector in recent years, various initiatives that have been launched to promote energy efficiency actions have not been as effective as expected. In this sense, as the INDUCE project has seen, it is necessary to distinguish between large enterprises and SMEs. Large companies have, in addition to the requirements of the regulations (i.e., the EED), the capacity to make investments and the sufficient resources to promote energy efficiency actions. However, over 98\% of companies in Europe are SMEs [7] (Figure 7), and given that they do not have to meet any regulatory requirements for energy efficiency, there is a need to further promote initiatives and to provide sufficient support tools. 


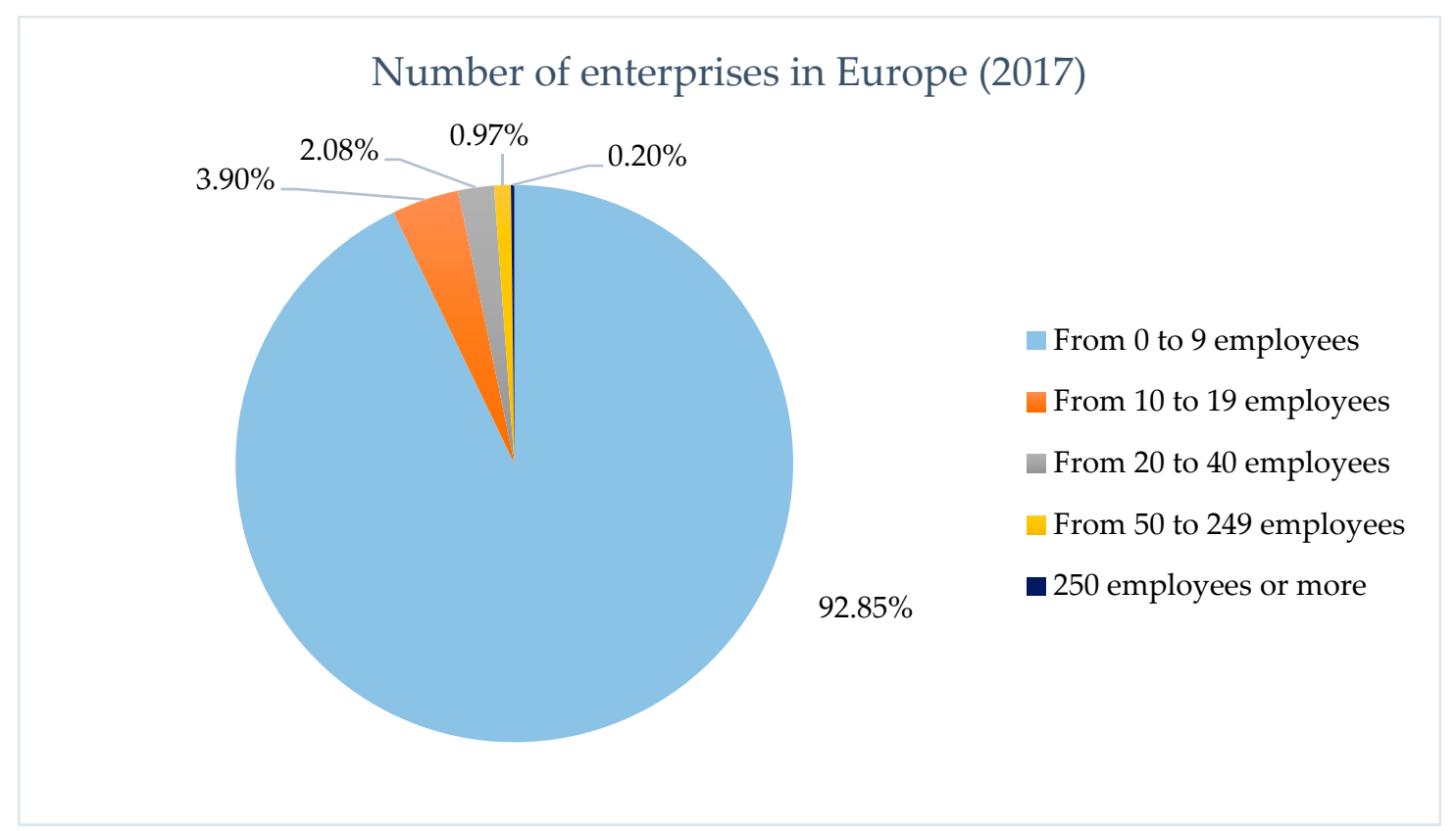

Figure 7. Overview of the enterprises in 2017 (EU-28) according to the number of employees (source: EUROSTAT [7]).

However, as per the analyses of the INDUCE project, it is not enough to implement actions to promote energy audits; instead, it is necessary to generate and provide new approaches that help companies to achieve their energy objectives and that generate some need for them. In this sense, considering the high diversity between sectors, subsectors, large enterprises, and SMEs in general, the needs and requirements that a company may have must be considered throughout the whole process. Hence, an open methodology has been provided for all types of companies, which is adapted to the needs and expectations of each of them. Therefore, although the results of the INDUCE project have been conclusive at the global level, and at the level of each of the companies involved, it is positive in addressing all aspects, whether energy, cultural, and behavioral. Thus, this new approach can be considered in line with existing and future initiatives that promote energy efficiency, as well as in line with what is required of the industrial sector in terms of energy efficiency, through the energy management system standard ISO 50001:2018, which considers the organizational orientation crucial [21]. In this sense, the INDUCE methodology could be promoted on the EU and Member State levels, e.g., programs that financially support energy audits could also include the cultural and company scan (see Figure 2).

In conclusion, the INDUCE methodology can be a very useful tool to promote energy efficiency in a company of any industrial or service activity in Europe, since it is totally flexible and adaptable to any circumstance, and it improves the results of the actions carried out. The only aspect that needs to be pointed out and can be considered in some cases as a barrier is that, although the methodology is flexible and adaptable to any case, the HCD approach is unique, so it has to be fully developed in order to achieve benefits.

Author Contributions: Formal analysis and investigation, G.M.; conceptualization and methodology, E.L. and J.G.; results, A.D. and T.H.; review, E.A. All authors read and agreed to the published version of the manuscript.

Funding: This contribution was developed within the framework of the INDUCE project "Towards a sustainable agro-food Industry: Capacity building programmes in Energy Efficiency," funded by the European Union under the H2020 Framework Programme, project number 785047.

Conflicts of Interest: The authors declare no conflict of interest. 


\section{Abbreviations}

$\begin{array}{ll}\mathrm{CO}_{2} & \text { Carbon dioxide } \\ \text { EED } & \text { European Energy Efficiency Directive 2012/27/EU } \\ \text { EEOSs } & \text { Energy efficiency obligation schemes } \\ \text { EMS } & \text { Energy management system } \\ \text { EU } & \text { European Union } \\ \text { GHG } & \text { Greenhouse gas } \\ \text { HCD } & \text { Human-centered design } \\ \text { ISO } & \text { International Standard Organization } \\ \text { NACE } & \text { Nomenclature of Economic Activities } \\ \text { SMEs } & \text { Small and medium enterprises }\end{array}$

\section{References}

1. European Parliament. EED. Directive 2012/27/EU of the European Parliament and of the Council of 25 October 2012 on Energy Efficiency. Off. J. Eur. Union 2012, 315, 1-56.

2. European Parliament. Directive 2018/2002/EU amending Directive 2012/27/EU on Energy Efficiency. Off. J. Eur. Union 2018, 328, 210-230.

3. Chan, Y.; Kantamaneni, R. Study on Energy Efficiency and Energy Saving Potential in Industry and on Possible Policy Mechanisms; ICF Consult. Ltd.: London, UK, 2015; pp. 1-461.

4. Monforti-Ferrario, F. Energy Use in the EU Food Sector: State of Play and Opportunities for Improvement; European Union; Joint Research Centre; Institute for Energy and Transport and Institute for Environment and Sustainability: Ispra, Italy, 2015.

5. Blasco Hedo, E. Real Decreto 56/2016, de 12 de febrero, por el que se transpone la Directiva 2012/27/UE del Parlamento Europeo y del Consejo, de 25 de octubre de 2012, relativa a la eficiencia energética, en lo referente a auditorías energéticas, acreditación de proveedo. Actual. Jurídica Ambient. 2016, 55, 39-41.

6. European Commission. Good Practice in Energy Efficiency-Clean Energy for all Europeans; Publications Office of the European Union: Luxembourg, 2017.

7. European Commission; Eurostat. Small and Medium-Sized Enterprises: An Overview; Eurostat Press Centre: Luxembourg, 2018; pp. 1-2.

8. Cagno, E.; Worrell, E.; Trianni, A.; Pugliese, G. A novel approach for barriers to industrial energy efficiency. Renew. Sustain. Energy Rev. 2013, 19, 290-308. [CrossRef]

9. 785047 INDUCE. Towards a Sustainable Agro-Food Industry: Capacity Building Programmes in Energy Efficiency-785047. 2017. Available online: https://cordis.europa.eu/project/id/785047 (accessed on 1 June 2020).

10. Wohlfarth, K.; Eichhammer, W.; Schlomann, B.; Mielicke, U. Learning networks as an enabler for informed decisions to target energy-efficiency potentials in companies. J. Clean. Prod. 2016, 163. [CrossRef]

11. Burk, A.; Baker, R. Measuring End-Use Technological and Behavioral Waste to Prioritize and Improve Program Design; International Energy Program Evaluation Conference: Chicago, IL, USA, 2013.

12. Jollands, N.; Tanaka, K.; Gasc, E.; Wescott, W. Energy Management Action NetworK (EMAK)-A Scoping Study Investigating the Establishment and Support of an International and Domestic Action Network of Energy Management in Industry; International Energy Agency: Paris, France, 2009.

13. Granade, C.; Creyts, J.; Derkach, A.; Farase, P.; Nyquist, S.; Ostrowski, K. Unlocking Energy Efficiency in the U.S. Economy; McKinsey \& Company: NewYork, NY, USA, 2009.

14. Fraunhofer ISI. Deliverable 2.4-Benchmarking Baseline Report Project Factsheet; 785047 INDUCE, European Union's H2020 Coordination Support Action; Fraunhofer ISI: Karlsruhe, Germany, 2018.

15. Kooger, R.S.M.; Reffeltrath, P. D2.2 Best Practice Guideline; 785047 INDUCE, European Union's H2020 Coordination Support Action: Amsterdam, The Netheralands, 2018.

16. Fraj, I.; Hermans, L. D2.1 Overview of Capacity Building and Training Programmes; 785047 INDUCE, European Union's H2020 Coordination Support Action: Amsterdam, The Netheralands, 2018.

17. IDEO.org. The Field Guide To Human-Centered Design, 1st ed.; IDEO.org: Palo Alto, CA, USA, 2015.

18. Fernandez, C. Learning from Japanese approaches to professional development: The case of lesson study. J. Teach. Educ. 2002, 53, 393-405. [CrossRef] 
19. Hiles, J.B. Teacher Learning Through the Dialogic Space of a Lesson Study Cycle; University of Pittsburgh School of Education: Pittsburgh, PA, USA, 2018.

20. Elliott, J. What is Lesson Study? Eur. J. Educ. 2019. Available online: https://lessonresearch.net/about-lessonstudy/what-is-lesson-study/ (accessed on 1 June 2020).

21. Javied, T.; Rackow, T.; Franke, J. Implementing energy management system to increase energy efficiency in manufacturing companies. Procedia CIRP 2015, 26, 156-161. [CrossRef]

22. ISO. ISO 50001-2018: Energy Management Systems-Requirements with Guidance for Use; International Organization for Standardization: Geneva, Switzerland, 2018; p. 47.

(C) 2020 by the authors. Licensee MDPI, Basel, Switzerland. This article is an open access article distributed under the terms and conditions of the Creative Commons Attribution (CC BY) license (http://creativecommons.org/licenses/by/4.0/). 